\title{
EXPERIMENTAL INVESTIGATION OF THE PROPERTIES OF LAMINATED NONWOVENS USED FOR PACKAGING OF POWDERS IN MINERAL WARMERS
}

\author{
E. Irzmańska1,*, M. Jurczyk-Kowalska², M. Bil², M. Płocińska² \\ 1 Department of Personal Protective Equipment, Central Institute for Labour Protection - National Research Institute, Wierzbowa 48, Łódź, Poland \\ 2 Faculty of Materials Science and Engineering, Warsaw University of Technology, Wołoska 141, 02-507 Warszawa, Poland \\ Coresponding author. E-mail: emirz@ciop.lodz.pl
}

\begin{abstract}
:
The study involved laminated nylon and viscose nonwovens, both perforated and non-perforated, with a view to using them for packaging of powders in mineral warmers. The nonwovens were examined in terms of morphology as well as tensile strength in dry and wet states. Thermal properties were determined by differential scanning calorimetry. Dynamic mechanical analysis was carried out in a broad range of temperatures. Surface wettability and water vapor permeability were assessed. The findings were analyzed to determine the utility of the studied materials as mineral warmer packaging materials in cold work or living environments.
\end{abstract}

\section{Keywords:}

Nonwovens, morphology, packaging, mechanical properties, hygienic properties, warmers

\section{Introduction}

Laminated nonwovens are technical textiles that are widely used in the clothing, pharmaceutical, and medical industries, primarily as packaging and protective materials as well as for disposable garments [1-4]. Polymeric nonwovens are lightweight, resistant to environmental conditions, and easy to sterilize. They can also be laminated to facilitate sealing and regulate permeability. Laminated nonwovens are applied as packaging materials, preventing the ingress of external factors and improving comfort in contact with the human body. Mineral warmers, which operate on the principle of iron oxidation, are used as inserts in protective and sports garments to increase thermal comfort in cold environments [5-9].

Mixtures of mineral compounds used in warmers contain iron, vermiculite, diatomite, salt, activated carbon, and water. Iron is directly responsible for the thermal effect due to oxidation, while salt and water accelerate the reaction. Vermiculite and diatomite, which are easily heated up, dissipate the heat throughout the volume of the warmer, while activated carbon aids in heat accumulation and absorbs any odors that may arise during the reaction [10-12].

From the application point of view, packaging for mineral compounds must meet several criteria, such as provide access to oxygen from the air in order to oxidize the iron within a specified period of time, protect the users from direct contact with the powder, and ensure user comfort. To enable oxygen access, laminated nonwovens are usually perforated. On the other hand, the packaging should restrict direct access of air to the mineral mixture as unconstrained exposure of the mineral compounds would result in dynamic heat release characterized by high temperature and short duration [13]. Nonwovens must be laminated to prevent excessive moisture loss during storage and use, and the packaging should also limit the ingress of external moisture as an excessive amount of water would hinder the thermal effect [5]. Packaging should be characterized by sufficient durability for safety reasons and be readily sealable under industrial conditions (e.g., by heat bonding). Indeed, packaging materials for thermally active mineral compounds are exposed to a number of challenging factors such as elevated temperature, moisture, and mechanical stress. To enable safe usage, it is essential that the materials remain stable in terms of their size and strength properties under these conditions.

The study involved laminated nylon and viscose nonwovens, both perforated and non-perforated, with a view to using them for packaging of powders in mineral warmers. The nonwovens were examined in terms of morphology as well as tensile strength in dry and wet states. Thermal properties were determined by differential scanning calorimetry (DSC). Dynamic mechanical analysis (DMA) was carried out in a broad range of temperatures. Surface wettability and water vapor permeability were assessed. The findings were analyzed to determine the utility of the studied materials as mineral warmer packaging materials in cold work or living environments. 


\section{Materials and methods}

\subsection{Materials}

The study involved two types of materials, laminated nylon and viscose nonwovens, both in perforated and non-perforated variants, with their basic characteristics given in Table 1. The nylon nonwoven (Unitika Ltd., Japan) was supplied by the manufacturer in both perforated and non-perforated forms. The laminate was made by heat bonding of a polyethylene (PE) film followed by cold perforation. The viscose nonwoven (Novita, Poland) was also laminated by heat bonding with PE, but it was perforated while hot. Images of the studied nonwovens are presented in Figures 1-6.

\subsection{Tests}

\subsubsection{Morphology}

The morphology of the studied materials was examined using a Hitachi SU-8000 scanning electron microscope (Japan). Samples were sputter coated with a conductive layer and examined at magnifications ranging from $\times 30$ to $\times 2,000$.

\subsubsection{Tensile strength}

Tensile strength was tested according to the standard EN ISO 13934-1 under wet and dry conditions [14]. Prior to experiments, samples were conditioned for $24 \mathrm{~h}$ in a standard atmosphere for dry tests and for $1 \mathrm{~h}$ in demineralized water at $21 \pm 1^{\circ} \mathrm{C}$ for wet tests. Tensile tests were conducted using a Zwick Z005 tester (Germany), equipped with a $5 \mathrm{kN}$ load cell. The samples were cut from a roll of material and measured $50 \times 300 \mathrm{~mm}$. They were loaded at a rate of $100 \mathrm{~mm} / \mathrm{min}$. The distance between the clamps holding samples was $200 \mathrm{~mm}$.

\subsubsection{Contact angle}

The hydrophilic properties of the surface were examined by determining contact angle for both sides of the samples (nonwoven and PE film) using $1 \mu \mathrm{L}$ distilled water droplets at $22^{\circ} \mathrm{C}$. Angles were measured by means of a DataPhysics goniometer (Germany) and OCA 20 software. The results provided are mean values from 10 droplets.
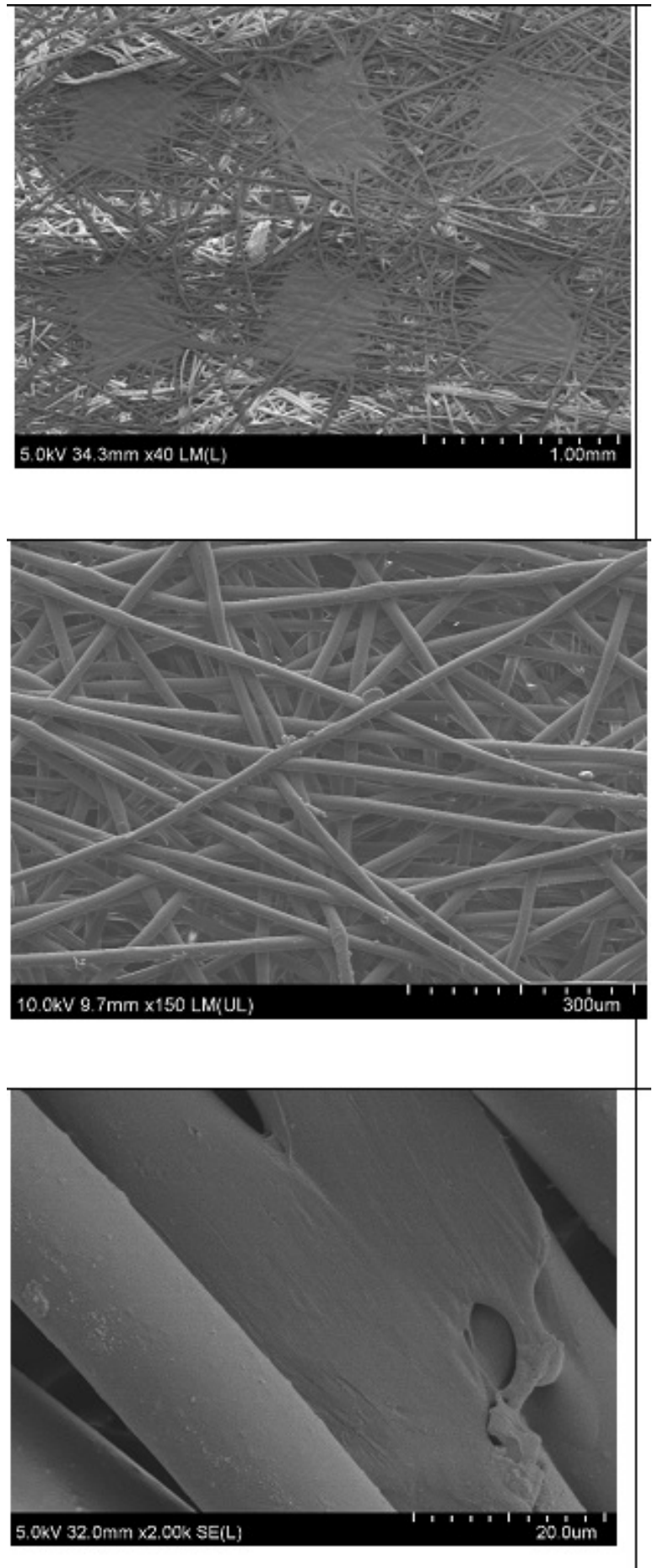

Figure 1. SEM images of nylon nonwoven.

Table 1. Basic characteristics of the studied materials

\begin{tabular}{|c|c|c|c|c|c|}
\hline No. & Sample code & Nonwovens & Surface mass, $\mathbf{g} / \mathbf{m}^{2}$ & Laminate & Perforation \\
\hline 1 & PA-L & PA 6 & 70 & PE & - \\
\hline 2 & PA-LP & PA 6 & PE & PE \\
\hline 3 & VIS-L & Viscose rayon & 85 & PE & - \\
\hline 4 & VIS-LP & Viscose rayon & & P \\
\hline
\end{tabular}

$\mathrm{PE}$, polyethylene. 



Figure 2. SEM images of viscose nonwoven.

\subsubsection{Water vapor permeability}

Water vapor permeability was evaluated in accordance with the standard PN-EN ISO 20345:2012 [15]. Fifteen samples were tested for each nonwoven variant. The samples were mounted over the opening of a vessel with a desiccant. The setup was exposed to a strong air low in a conditioned atmosphere. The desiccant inside the vessel was continuously mixed with the air by spinning. After the test, the vessel was weighed to determine the weight of moisture that permeated a given sample and was absorbed by the desiccant. Water vapor permeability was calculated from the following formula:

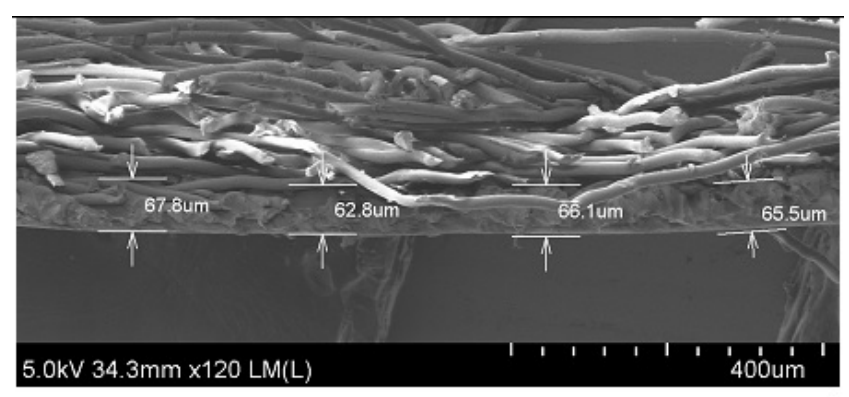

Figure 3. SEM image of cross-section of laminated nylon nonwoven

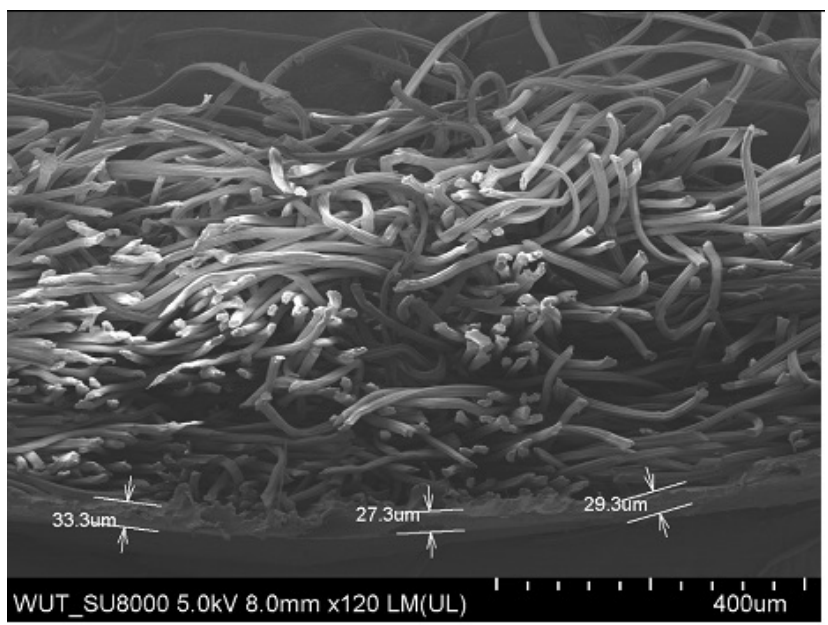

Figure 4. SEM image of cross-section of laminated viscose nonwoven

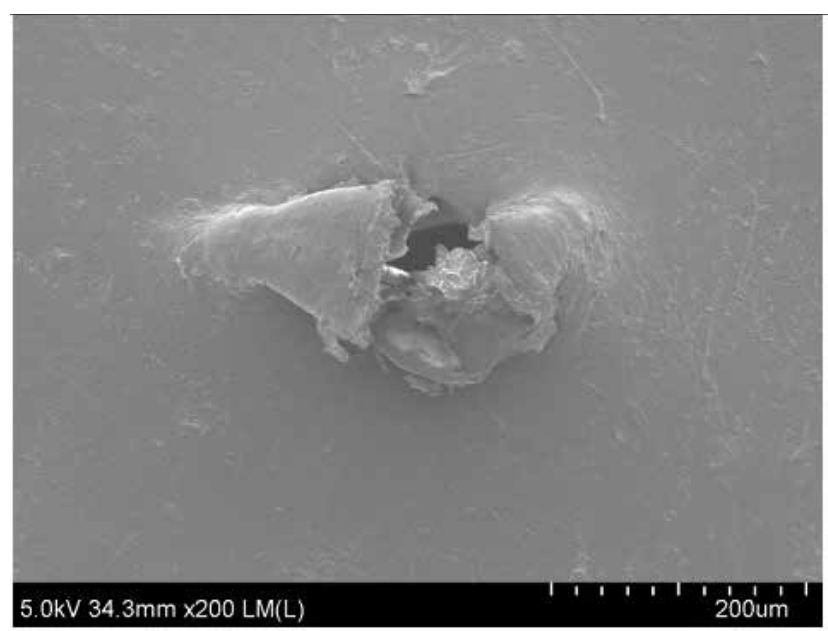

Figure 5. SEM image of PA-LP sample surface on the laminated side

$$
W_{3}=\frac{m}{A t}=\frac{m}{\pi r^{2} t}
$$

where $W_{3}$ is the water vapor permeability $\left(\mathrm{mg} /\left(\mathrm{cm}^{2} \times \mathrm{h}\right)\right), m$ $m_{2}-m_{1}(\mathrm{mg}), m_{1}$ the initial weight of the vessel including the tested sample and silica gel $(\mathrm{mg}), m_{2}$ the final weight of the vessel including the tested sample and silica gel $(\mathrm{mg})$, $A=\pi r^{2}=$ the surface area of the sample $\left(\mathrm{cm}^{2}\right), r$ the radius of 


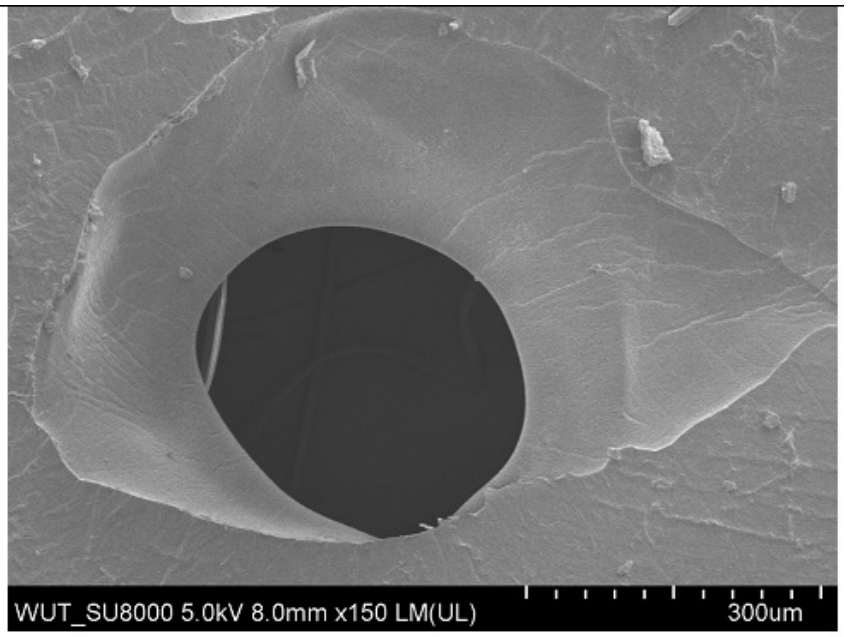

Figure 6. SEM image of VIS-LP sample surface on the laminate side

the sample $(\mathrm{cm})$, and $t$ the time interval between the first and second weighing.

Acceptable water vapor permeability was defined as not less than $2.0 \mathrm{mg} /(\mathrm{cm} \times \mathrm{h})$.

\subsubsection{Thermal analysis (DSC)}

Thermal properties were determined using a DSC Q5000 differential scanning calorimeter (TA Instruments, USA). Samples weighing $10 \pm 2 \mathrm{mg}$ were heated at a rate of $10^{\circ} \mathrm{C} /$ min from $-50^{\circ} \mathrm{C}$ to $250^{\circ} \mathrm{C}$ in a heating/cooling/heating pattern. Tests were performed not only for the laminate as a whole but also for the nonwovens and PE films obtained by mechanical separation of the two layers.

\subsubsection{Dynamic mechanical analysis}

Mechanical properties were evaluated over a broad range of temperatures by means of a DMA. A DMA Q800 analyzer (TA Instruments, USA) was used in the tension film mode. Samples in the form of strips measuring $20 \times 5 \times 0.15 \mathrm{~mm}$ were heated at a rate of $3^{\circ} \mathrm{C} / \mathrm{min}$ in the temperature range from $-50^{\circ} \mathrm{C}$ to $170^{\circ} \mathrm{C}$. While heating, the material was deformed at a constant amplitude of $20 \mu \mathrm{m}$ and a frequency of $10 \mathrm{~Hz}$. Based on obtained data it possible to determine the storage modulus $\left(E^{\prime}\right)$, the loss modulus ( $\left.E^{\prime \prime}\right)$, and the tangent of the phase angle $(\tan \delta)\left(E^{\prime \prime} / E^{\prime}\right)$.

\section{Results and Discussion}

\subsection{Morphology}

The nonwovens differed significantly in their fiber morphology. The surface microstructure of laminated nonwovens is shown in Figures 1 and 2, and their cross-sections are presented in Figures 3 and 4 .

Microscopic examinations have revealed that the studied nonwovens differ significantly in terms of fiber morphology. The nylon nonwoven (Figure 1 ) is made of smooth fibers, circular in cross-section, with a diameter of $20 \mu \mathrm{m}$, which are oriented as a result of the production process. It is characterized by evenly distributed bond points created by bonding with PE film [1]. The viscose rayon fibers have revealed a more complex surface typical of cellulose materials [16]. Fibers ranging in diameter from 15 to $20 \mu \mathrm{m}$ are arranged in a disordered, chaotic manner (Figure 2). No bonding-related changes can be seen.

Figures 3 and 4 present the cross-sections of the studied nonwovens with the thickness of the bonded film marked in the images (62-71 $\mu \mathrm{m}$ for the nylon laminate and 25-35 $\mu \mathrm{m}$ for the viscose laminate). In addition, differences in nonwoven thickness were found (approximately $550 \mu \mathrm{m}$ for viscose rayon and $300 \mu \mathrm{m}$ for nylon).

Perforations in the outer surface of PE film are shown in Figures 5 and 6 for the two materials studied. Cold perforation led to cracks in the PE film, while hot perforation resulted in regular openings with a diameter of approximately $400 \mu \mathrm{m}$.

\subsection{Analysis of tensile strength}

Samples were examined both in dry and wet states. Tensile strength results are presented in Figure 7, and examples of stress-strain curves are given in Figures 8 and 9.

Laminated nylon nonwovens were characterized by higher tensile strength than their viscose counterparts both under dry and wet conditions. It was found that in laminated nylon nonwovens, PE perforation resulted in higher tensile strength (that effect was not identified in laminated viscose materials). Wet samples exhibited lower strength, by approximately $30 \%$ for the nylon laminate and by more than $55 \%$ for the viscose laminate.

\subsection{Analysis of surface wettability}

An important factor determining the thermal effect in oxidationbased mineral warmers is the availability of moisture from the air and the presence of water in the reaction mixture. Thus, the hydrophilicity of materials used in mineral warmer packaging significantly affects their functionality. Hydrophilicity was evaluated based on contact angle (only for non-perforated laminates), with the results given in Table 2.

Table 2. Contact angle results

\begin{tabular}{|c|c|c|}
\hline \multirow{2}{*}{ Sample } & $\begin{array}{c}\text { Surface } \\
\text { examined }\end{array}$ & $\begin{array}{c}\text { Contact angle, } \\
{\left[^{\circ}\right] \pm \text { SD }}\end{array}$ \\
\hline $\begin{array}{c}\text { Laminated nylon } \\
\text { nonwoven }\end{array}$ & Nonwoven & $111 \pm 5$ \\
\cline { 2 - 3 } & PE film & $62 \pm 2$ \\
\hline $\begin{array}{c}\text { Laminated } \\
\text { viscose nonwoven }\end{array}$ & Nonwoven & - \\
\cline { 2 - 3 } & PE film & $86 \pm 4$ \\
\hline
\end{tabular}

$\mathrm{SD}$, standard deviation; PE, polyethylene. 


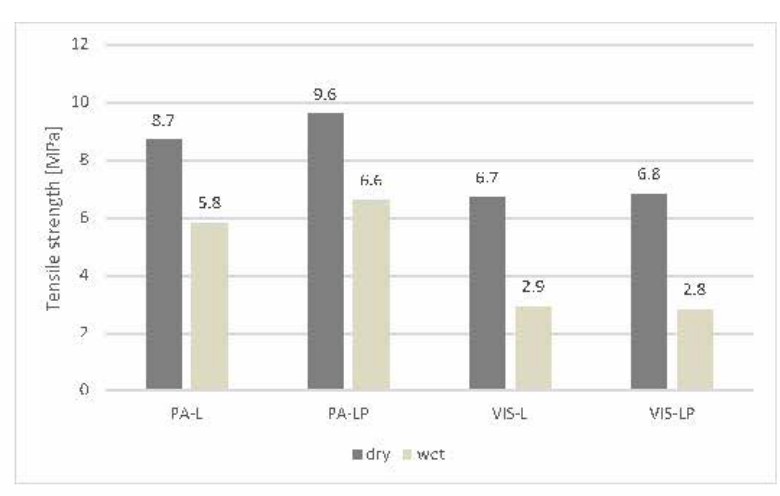

Figure 7. Tensile strength of laminated nylon and viscose nonwovens.

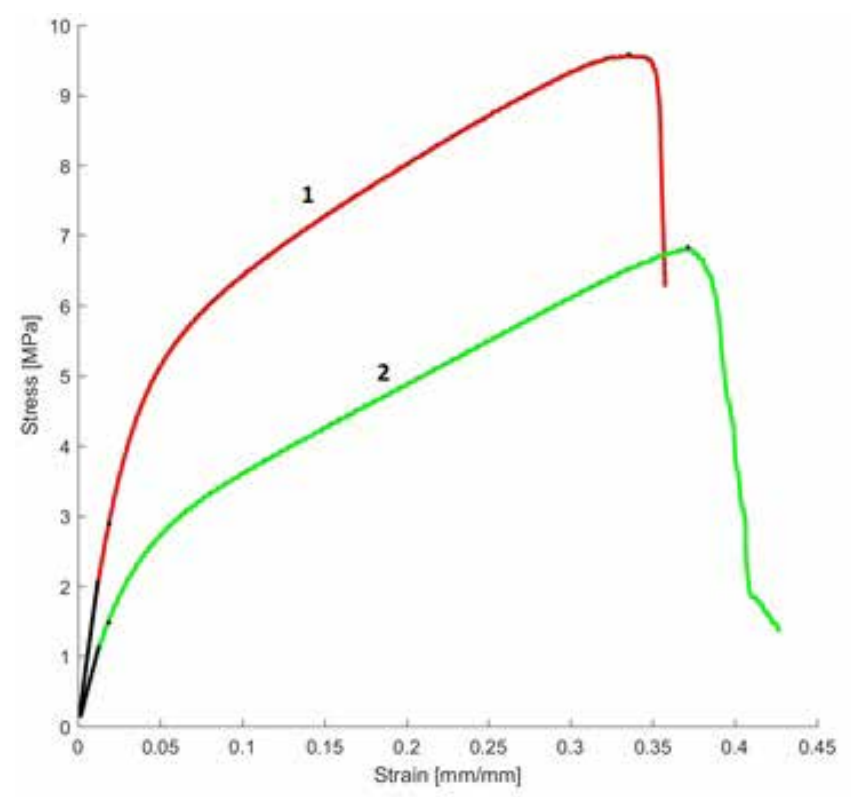

Figure 8. Stress-strain curve for perforated laminated nylon nonwovens: 1) dry and 2) wet.

In the case of the nylon laminate, the study showed that the nonwoven layer (located on the outer side of the warmer packaging) was hydrophobic with a contact angle of $111^{\circ}$, while the PE film (coming in direct contact with the mineral powder) was moderately hydrophilic with a contact angle of $68^{\circ}$. It was not possible to measure the contact angle for the viscose nonwoven as water droplets were immediately absorbed by it. On the other hand, the PE film bonded to its surface exhibited moderately hydrophobic properties with a contact angle of



Figure 9. Stress-strain curve for laminated viscose nonwovens: 1) perforated and 2) non-perforated.

$86^{\circ}$. Thus, the studied materials were found to show marked differences in their surface properties.

\subsection{Analysis of water vapor permeability}

Water vapor permeability results for the studied materials were statistically analyzed using SPSS Statistics 25.0 to identify significant differences between the four material variants. Analysis of variance (ANOVA) was conducted using a posteriori bootstrapping ( 1,000 replicates) with the Bonferroni test for post hoc comparisons. Descriptive statistics and ANOVA results are given in Table 3.

A statistically significant correlation was found between material variant and water vapor permeability. The perforated laminates VIS-LP and PA-LP exhibited higher permeability than their non-perforated counterparts. In addition, PA-LP was more permeable than VIS-LP, while PA-L was less permeable than VIS-L, as can be seen from Figure 10. Given the larger perforation openings in the viscose laminates (Figures 5 and 6 ), their lower permeability may be attributable to the fact that some of the moisture can be absorbed by the viscose nonwoven during measurement.

Table 3. Descriptive statistics and ANOVA for the relationship between water vapor permeability and material variant

\begin{tabular}{|c|c|c|c|c|c|c|c|c|c|}
\hline \multirow{2}{*}{ Parameter } & & \multicolumn{4}{|c|}{ Material variant } & \multirow{2}{*}{ Post hoc test } & \multirow{2}{*}{$F(1,8)$} & \multirow{2}{*}{$\mathbf{p}$} & \multirow{2}{*}{$\eta^{2}$} \\
\hline & & VIS-L & VIS-LP & PA-L & PA-LP & & & & \\
\hline $\begin{array}{l}\text { Water vapor } \\
\text { permeability }\end{array}$ & M & 7.07 & 29.93 & 0.57 & 40.87 & $\begin{array}{l}\text { VIS-LP > VIS-L, PAL-L } \\
\text { PA-LP > VIS-L, PAL-L }\end{array}$ & $1,613.57$ & 0.001 & 0.98 \\
\hline $\mathrm{P}\left(\mathrm{mg} / \mathrm{cm}^{2} \times \mathrm{h}\right)$ & SD & 0.87 & 1.27 & 0.25 & 0.49 & $\begin{array}{c}\text { VIS-LP }<\text { PA-LP } \\
\text { VIS-L }>\text { PA-L }\end{array}$ & & & \\
\hline
\end{tabular}

ANOVA, analysis of variance; $M$, mean; SD, standard deviation. 


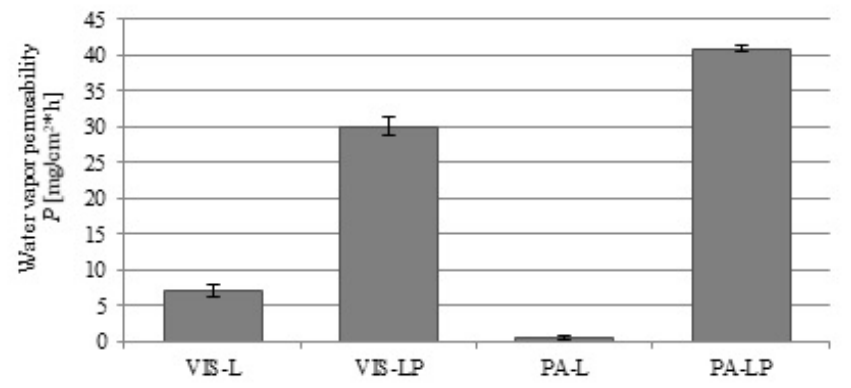

Figure 10. Water vapor permeability for the studied materials.

\subsection{Analysis of thermal and thermomechanical properties}

The thermal properties of the studied nonwovens and laminates were evaluated using DSC. The obtained thermograms were used to evaluate glass transition temperature $T_{g}$, melting points $T_{m}$, and crystallization points $T_{k}$ and to determine the enthalpy of phase transitions. The results are presented in Figures 11 and 12 .

The studied materials have been found to differ markedly in their thermal characteristics. PA-L exhibits the presence of glass transition and two endothermic transitions at higher temperatures responsible for crystalline phase melting (Figure 11). The glass transition temperature $\left(T_{q}\right)$ for $P A-L$ is $41^{\circ} \mathrm{C}$. PE melting is reflected by a broad peak with two maxima at $105^{\circ} \mathrm{C}$ and $120^{\circ} \mathrm{C}$, while nylon melting is associated with a narrow peak with one maximum at $219^{\circ} \mathrm{C}$. DSC analysis performed separately for the nylon nonwoven (PA) has revealed that the endothermic transition characterized by a broad peak with a maximum at approximately $60^{\circ} \mathrm{C}$ in the first heating cycle is associated with the $T_{g}$ of nylon, which is obscured by a peak attributable to moisture or other substances that may be present in the commercially available product [17]. In turn, the endothermic peak above $200^{\circ} \mathrm{C}$ reflects crystalline phase melting in the nylon nonwoven.
DSC analysis of the viscose laminate has revealed (VIS-L) a broad endothermic peak in the first heating cycle with a maximum at $89.9^{\circ} \mathrm{C}$. For the nonwoven itself (VIS), the endothermic peak maximum is $73.8^{\circ} \mathrm{C}$. The upward shift in that maximum in the laminated material is associated with the melting point of the crystalline phase in the PE film. Thermograms for the second heating cycle do not indicate any endothermic transitions with a broad peak (Figure 12). The broad peak recorded for the VIS sample is mostly attributable to the thermal decomposition of viscose rayon accompanied by carbon dioxide release [18].

Thermomechanical studies were conducted to evaluate the mechanical properties of the samples as a function of temperature. DMA was used to determine the viscoelastic properties of materials subjected to periodic deformations under conditions of temperature change. These properties are described using the storage modulus ( $\left.E^{\prime}\right)$ reflecting elastic properties and the loss modulus (E") reflecting viscous properties. The ratio of the viscous modulus to the elastic modulus is known as the mechanical loss factor, $\tan \delta=$ E"/E'. Figures 13 and 14 show DMA results for the laminated nonwovens with perforation.

DMA results were used to compute $E^{\prime}$ for temperatures of $15^{\circ} \mathrm{C}$ and $37^{\circ} \mathrm{C}$. The laminated nylon nonwoven exhibits much higher rigidity ( $E^{\prime}$ from 322 to $259 \mathrm{MPa}$, see Figure 13 ) as compared to the laminated viscose nonwoven ( $E^{\prime}$ from 9 to $6 \mathrm{MPa}$, see Figure 14). In the latter case, the low values of the modulus are attributable to the processes of nonwoven melting and degradation at very low temperatures, as shown by DSC analysis. The DMA curves obtained for the two studied materials are very different, with the laminated nylon nonwoven showing stable mechanical properties over a wider temperature range.

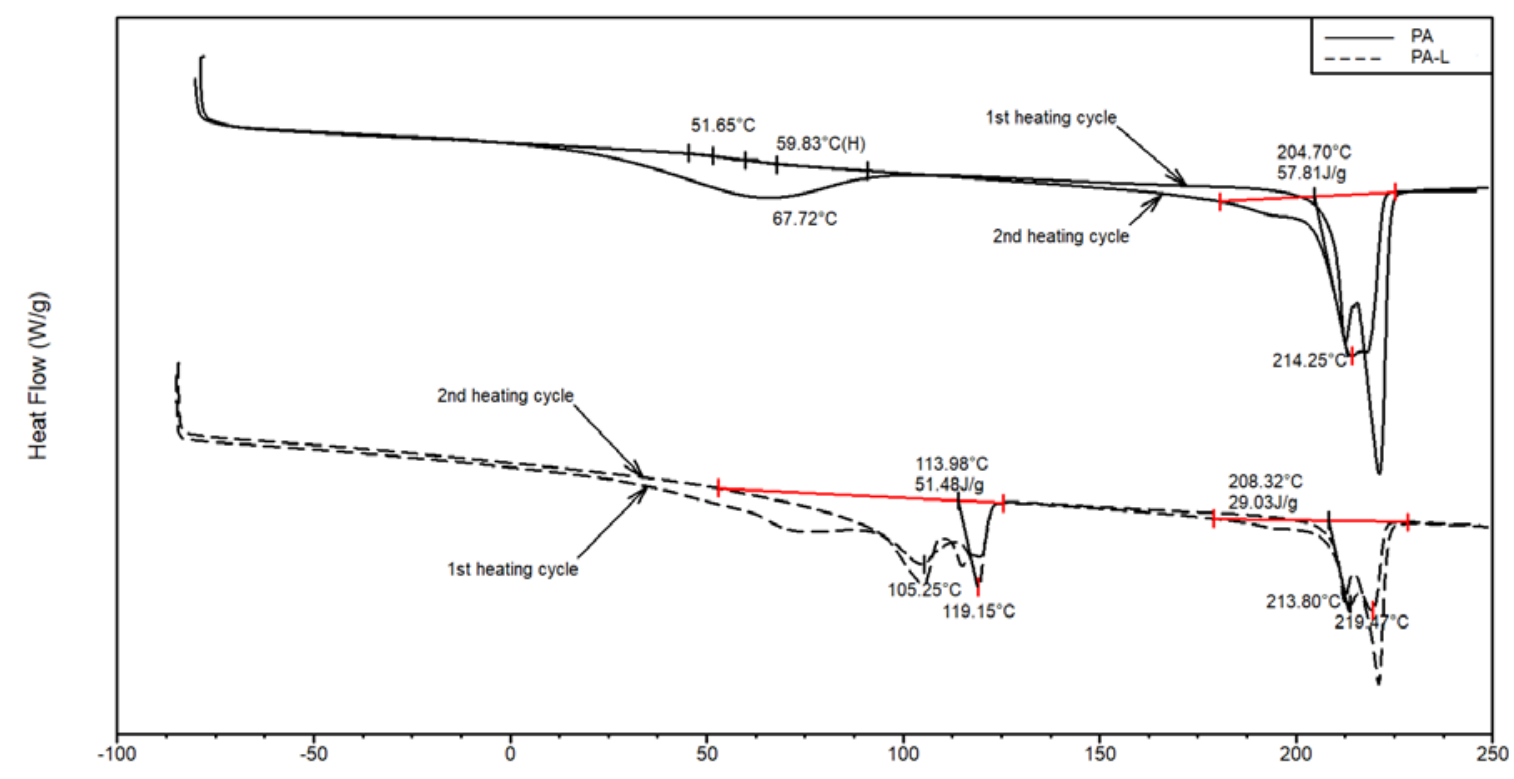

Figure 11. DSC spectra of laminated nylon nonwovens 


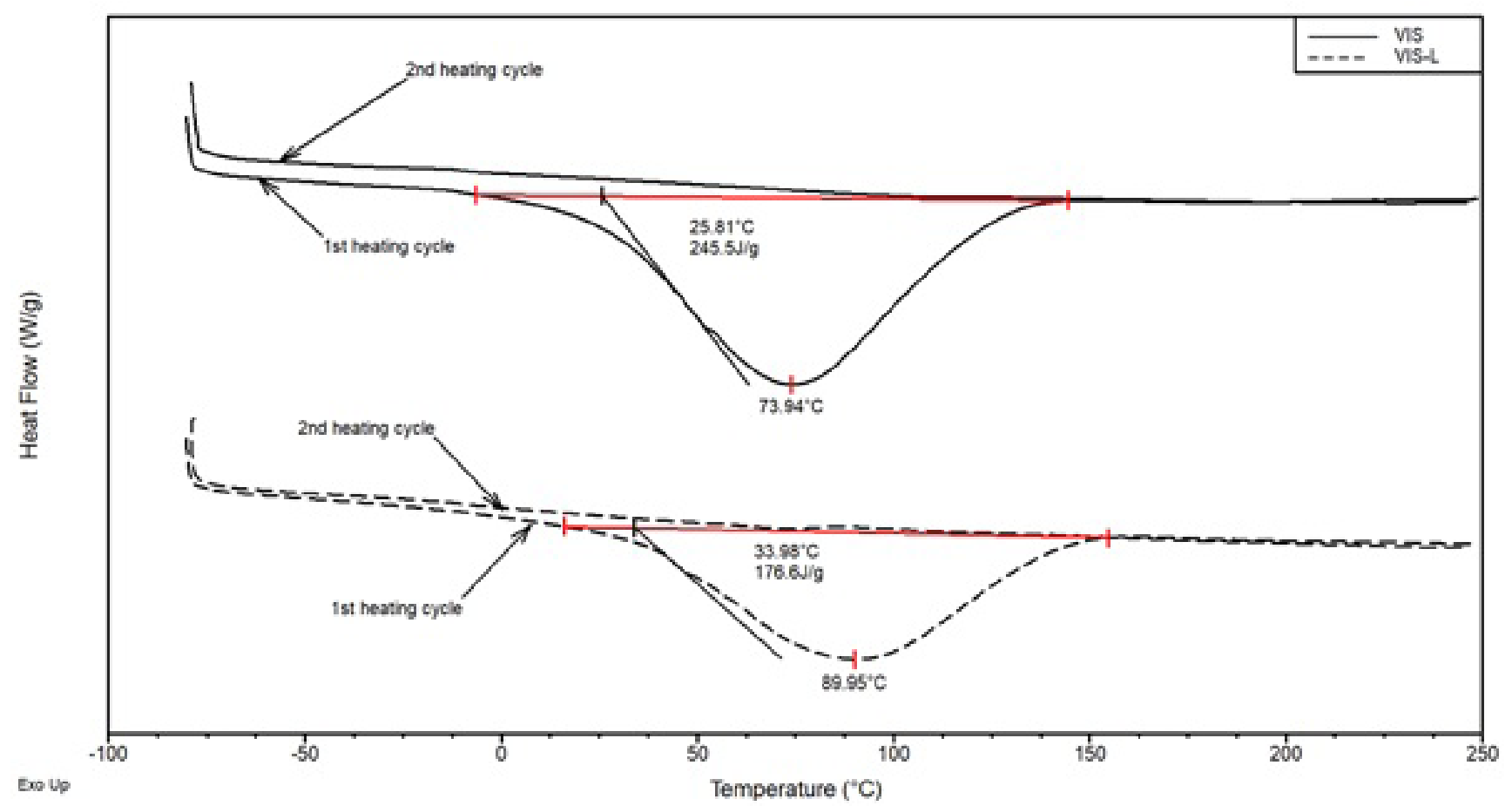

Figure 12. DSC spectra of laminated viscose nonwovens

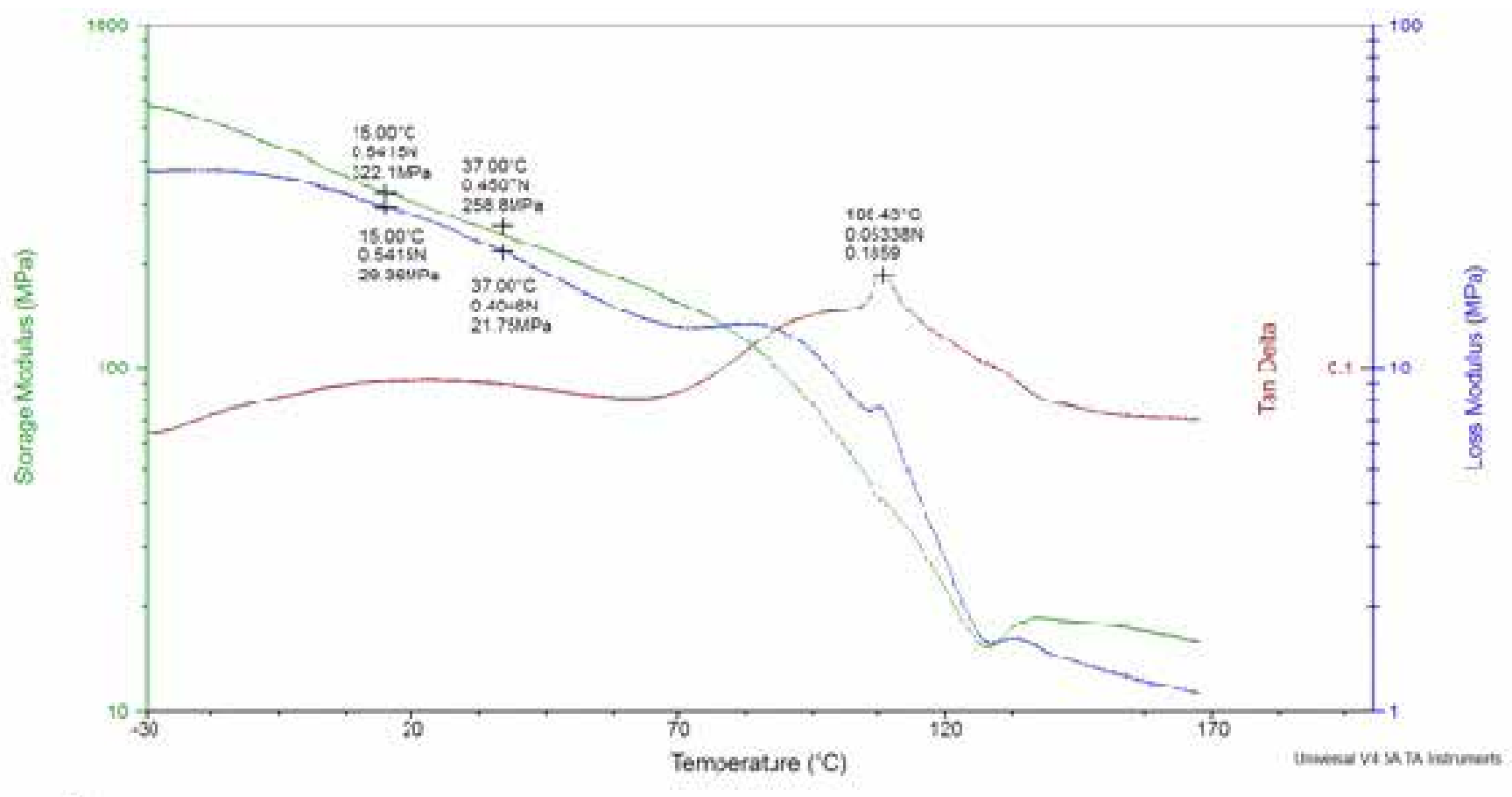

Figure 13. DMA showing the loss modulus ( $E ")$, the storage modulus ( $\left.E^{\prime}\right)$, and the loss factor (tan $\left.\delta\right)$ for laminated nylon nonwovens

\section{Conclusions}

The investigations presented in this work focused on determining the physical and thermomechanical properties of materials used for the packaging of powdered compounds in mineral warmers. The examined laminated nylon and viscose nonwovens and their variants significantly differed in their characteristics. The obtained results have made it possible to identify materials meeting high functional requirements.
Microstructural examinations revealed the typical morphology of nylon and viscose rayon fibers. The overall thickness of PA-L samples was lower than that of VIS-L ones, while film thickness was greater in PA-L samples, improving their mechanical properties. Indeed, it was found that the strength and elasticity of the tested laminates were mostly attributable to the characteristics of the PE film. In addition, thermomechanical tests showed that the properties of the nylon nonwoven were not only superior but also more stable over a wider temperature 


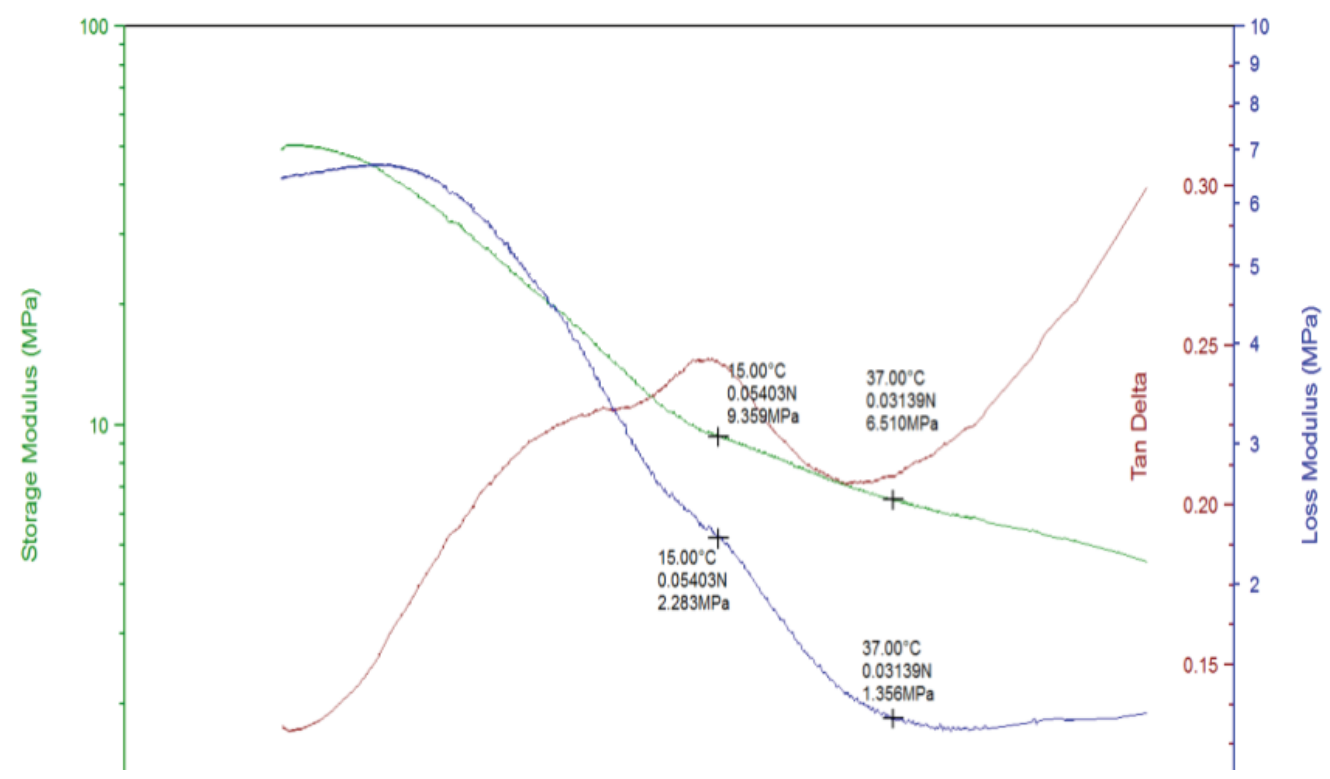

Figure 14. DMA showing the loss modulus ( $E ")$, the storage modulus ( $\left.E^{\prime}\right)$, and the loss factor $(\tan \delta)$ for laminated viscose nonwovens

range, which is critical for the packaging of thermally active powders.

Given that hydrophilicity is a major factor affecting the performance of materials used for mineral warmer packaging, it was found that the viscose nonwoven had high water absorption capacity and as such it should not prevent the permeation of moisture from the environment. Finally, the perforated variants of the laminates (VIS-LP and PA-LP) offered greater water vapor permeability than their non-perforated counterparts (VIS-L and PA-L), with the PA-LP material being the most permeable.

\section{Acknowledgment}

The paper is based on the results of COLDPRO project: 'The use of active ecological mineral compounds in the production of cold-protective gloves and footwear' funded in the years 20152018 by the National Centre for Research and Development.

\section{References}

[1] Kansal, H. (2016). Experimental investigation of properties of polypropylene and non-woven spunbond fabric. Journal of Polymer and Textile Engineering, 3(5), 8-14.

[2] Razzaque, A., Tesinova, P., Hes, L. (2019). Enhancement of hydrostatic resistance and mechanical performance of waterproof breathable laminated fabrics. Autex Research Journal, 19(1), 44-53.

[3] Kiekens, P., Van der Burght, E., Kny, E., Uyar, T., Milašius, R. (2014). Functional textiles - from research and development to innovations and industrial uptake. Autex Research Journal, 14(4), 219-225.

[4] Cybulska, M., Snycerski, M., Ornat, M. Qualitative evaluation of protective fabrics. Autex Research Journal, 2(2), 69-77.
[5] Sands, W. A., Kimmel, W. L., Wurtz, B. R., Stone, M. H., McNeal, J. R. (2009). Comparison of commercially available disposable chemical hand and foot warmers. Wilderness \& Environmental Medicine, 20(1), 33-38.

[6] Irzmańska, E., Bacciarelli-Ulacha, A. (2019). Effects of simulated pressure of wooden, plastic, and metal materials on the thermal insulation of cold-protective gloves of various designs. Textile Research Journal, 89(19-20), 4060-4070.

[7] Irzmanska, E., Bacciarelli-Ulacha, A. (2020). Case study: Measuring thermal insulation of heated protective gloves on a thermal hand model. Fibres \& Textile in Eastern Europe, in press.

[8] Irzmanska, E., Kropidlowska, P., Adamus-Włodarczyk, A. (2020). Chemical hand warmers in protective gloves: Design and usage. Autex Research Journal, in press.

[9] Matusiak, M., Kowalczyk, S. (2014). Thermal-insulation properties of multilayer textile packages. Autex Research Journal, 14(4), 299-307.

[10] Yamashita, Y., Shimizu, M. (1976). Structure of warmer. 3,976,049, 24-Aug-1976.

[11] Podella, C. W. (1988). Chemical heating pad with differing air-admitting perforation sets for different heat-generation levels. 4,756, 299, 12-Jul-1988.

[12] Klarzak, I., Ura-Bińczyk, E., Płocińska, M., JurczykKowalska, M. (2018). Effect of temperature and humidity on heat effect of commercial chemical warmers based on iron powder. Thermal Science and Engineering Progress, 6, 87-94.

[13] Brooks, B., Deakin, C. D. (2017). Relationship between oxygen concentration and temperature in an exothermic warming device. Emergency Medical Journal, 34(7), 472474.

[14] EN ISO 13934-1:2002. (2002). Textiles -Tensile properties of fabrics-Part 1: Determination of maximum force and elongation at maximum force using the strip method. 
[15] EN ISO 20345:2011. (2011). Personal protective equipment - safety footwear.

[16] Scholz, R., Herbig, F., Beck, D., Spörl, J., Hermanutz, F., et al. (2019). Improvements in the carbonisation of viscose fibres. Reinforced Plastics, 63(3), 146-150.

[17] Ting, T. M., Nasef, M. M., Hashim, K. (2015). Tuning $N$-methyl-D-glucamine density in a new radiation grafted poly(vinyl benzyl chloride)/nylon-6 fibrous boron-selective adsorbent using the response surface method. RSC Advances, 5(47), 37869-37880.

[18] Gurudatt, K., Tripathi, V. S. (1998). Studies on changes in morphology during carbonization and activation of pretreated viscose rayon fabrics. Carbon, 36(9), 13711377. 